\title{
Decline of rheumatologic care of nursing home residents with rheumatoid arthritis
}

\author{
Michael Schirmer $^{1}{ }^{\mathbb{D}} \cdot$ Vivienne Lion $^{1}$
}

Received: 28 August 2017 / Accepted: 30 August 2017 / Published online: 8 September 2017

(c) Springer-Verlag GmbH Germany 2017

\begin{abstract}
"Rheumatologic care is already infrequent in elderly patients with rheumatoid arthritis (RA) and further decreases after admission of the patients to a nursing home" [1]. This shocking comment is argued in this issue of Rheumatology International by Ramos et al., who provide deep insights into the problem that rheumatologic visits decrease by $48 \%$ and prescription of conventional synthetic disease-modifying antirheumatic drugs (DMARDs) by $26 \%$ after admission to a nursing home. Treatment by rheumatologists and prescription of antirheumatic drugs decreased significantly in the year after admission (rheumatologic visits: 17.6 to $9.1 \%$, bDMARDs: 2.1 to $1.5 \%$, csDMARDs: 22.5 to $16.5 \%$, glucocorticoids: 46.5 to $43.1 \%$, NSAIDs: 47.4 to $38.5 \%$ ).

In fact, this report leads us to an interdisciplinary challenge for the rheumatologic care of our RA-patients. These patients have made life-long payments for their medical insurance, and are still insured. Rheumatologists, general practitioners as well as geriatricians should now be competent partners of RA-patients not only outside, but also inside the nursing homes. A greater chance to have rheumatologic care in the nursing homes have those RA-patients, who had rheumatologic care already before admission, and the patients without rheumatologic care are at high risk of insufficient treatment for their RA. As a consequence, RApatients should be referred to rheumatologic care already before admission to a nursing home especially in case of suspected RA. And then, as the European population will become older in the future, adequate rheumatologic care in nursing homes will have to be improved in the future.
\end{abstract}

Michael Schirmer

michael.schirmer@i-med.ac.at

1 Department of Internal Medicine, Clinic II, Medical University Innsbruck, Innsbruck, Austria
A clear solution for this type of rheumatologic care in nursing homes has not been identified so far. We speculate, that the community principally has two independent options, probably both of them to be applied together in the future: (1) to educate professionals and refer patients to professionals, depending on their needs, whether they need a rheumatologist or a rheumatology-trained nurse; and (2) to educate mobile RA-patients for the use of RA-specific technical advices and e-services to reduce the need for professionals whenever possible. In general, a variety of devices and IT-based applications already exist that could be further specified for RA to be applied in nursing homes [2]. Unfortunately, this step is often limited by costs but should be re-evaluated in view of the data by Ramos et al.

Concerning the first approach of more professionals needed, already in 2011 the European League Against Rheumatism (EULAR) worked on international recommendations and proposed future research on the role of nurses in the management of chronic inflammatory arthritis [3]. In nursing homes, nurses specialised in rheumatology care may be able to take over an important role for RA-patients especially when in remission or with low disease activity, and for the management of comorbidity and extra-articular manifestations [4]. Although agreement with these recommendations is high, application differs across regions and could be increased [5]. Given the limited number of rheumatologists in many countries, this approach could be seen as a first step to improve care of RA-patients in nursing homes. Also, the quality perceived by the patients may be increased as observed in rheumatology departments with nursing clinics compared to those without nursing clinics [6].

Taken together, the study by Ramos et al. has to be considered as an alarming sign that nursing homes need more specific care for their RA-patients, either by personnel or technical support. This demand also applies to Western 
countries with insured RA-patients, and may even increase in the future. Structured nursing programmes to train nursespecialists [7] could support the effective implementation of rheumatologic care in nursing homes, possibly as a mobile nursing service specialised in rheumatologic care.

\section{References}

1. Luque Ramos A, Albrecht K, Zink A, Hoffmann F (2017) Rheumatologic care of nursing home residents with rheumatoid arthritis: a comparison of the year before and after nursing home admission. Rheumatol Int. doi:10.1007/s00296-017-3791-5

2. Crossen-Sills J, Toomey I, Doherty ME (2009) Technology and home care: implementing systems to enhance aging in place. Nurs Clin North Am 44:239-246. doi:10.1016/j.cnur.2009.03.003

3. van Eijk-Hustings Y, van Tubergen A, Boström C et al (2012) EULAR recommendations for the role of the nurse in the management of chronic inflammatory arthritis: table 1 . Ann Rheum Dis 71:13-19. doi:10.1136/annrheumdis-2011-200185

4. van der Kluit MJ, Ros WJG, Schrijvers AJP (2014) Nurse-led clinics for patients with chronic diseases in hospital and transmural care organizations. Clin Nurse Spec 28:332-342. doi:10.1097/ NUR.0000000000000079

5. van Eijk-Hustings Y, Ndosi M, Buss B et al (2014) Dissemination and evaluation of the European League Against Rheumatism recommendations for the role of the nurse in the management of chronic inflammatory arthritis: results of a multinational survey among nurses, rheumatologists and patients. Rheumatology (Oxford) 53:1491-1496. doi:10.1093/rheumatology/keu134

6. Muñoz-Fernández S, Aguilar MD, Almodóvar R et al (2017) SCORE study: quality indicators for rheumatology nursing clinics. Rheumatol Int 37:353-361. doi:10.1007/s00296-016-3644-7

7. Roussou E, Iacovou C, Georgiou L (2012) Development of a structured on-site nursing program for training nurse specialists in rheumatology. Rheumatol Int 32:1685-1690. doi:10.1007/ s00296-011-1869-Z 